\title{
Dermis fat grafts for bilateral augmentation mammaplasty
}

John Michael Drever MD FRCSC

Etobicoke General Hospital, Etobicoke, Ontario

JM Drever. Dermis fat grafts for bilateral augmentation mammaplasty. Can J Plast

Surg 1995;3(3):145-149. Dermis fat grafts for body contouring have been used for over a century and extensively reported and researched, but since the advent of the more reliable silicone implants they have been dropped and neglected. As a consequence of the present controversy surrounding silicone breast implants, women are inquiring about augmentation with their own tissues. Healthy patients with good vascularity are the best candidates. These grafts are removed from the lower abdomen and placed with the dermis side facing the muscle, 'take' and then lose about 30 to $50 \%$ of their initial volume. Thirty-six cases were performed with this technique, and a two-and-a-half year follow-up with few complications and a high level of satisfaction is reported.

Key Words: Augmentation mammaplasty, Autogenous tissues, Dermis fat grafts

\section{Greffe de peau d'épaisseur totale pour addition mammaire bilatérale}

RÉSUMÉ : Les greffes de peau d'épaisseur totale sont utilisées en chirurgie esthétique depuis plus d'un siècle et ont fait l'objet de nombreux rapports et essais, mais depuis l'avènement des implants de silicone, jugés plus fiables, elles avaient été abandonnées et reléguées au second plan. Par suite de la controverse qui entoure actuellement les implants mammaires faits de silicone, les femmes se renseignent au sujet de l'addition mammaire faite à partir de leurs propres tissus. Les patientes en santé et bien vascularisées sont les meilleures candidates. Ces greffons sont prélevés dans la partie inférieure de l'abdomen et placés le derme face au muscle, ils prennent, puis perdent environ 30 à $50 \%$ de leur volume initial. Trente-six cas ont été opérés au moyen de cette technique et le suivi d'une durée de deux ans et demi fait état de peu de complications et d'un taux élevé de satisfaction.

The first attempt at fat grafts found in the literature was described by Neuber (1) in 1893. He successfully used small fat grafts in cosmetic operations about the orbit. A few years later Czerny (2) became famous when he reported the successful transplantation of a large lipoma to replace the breast tissue removed after a subcutaneous mastectomy for chronic cystic mastitis. Lexer (3) in 1910 established fat grafting as an accepted clinical procedure by utilizing grafts for the correction of a wide variety of conditions. Since that time, numerous reports on the use of autogenous and even 
homologous fat grafts have appeared in the literature. Presently fat grafts and dermis fat grafts (DFGs) are commonly used by neurosurgeons and orthopaedic surgeons (4-6) during spinal and other bone surgery and by ophthalmologists $(7,8)$ for grafting in and around the orbits. Plastic surgeons have been using them in the face and neck area for many years, and some have used them for breast augmentation (9-11).

Peer and Walker $(12,13)$ did an interesting human study on the survival of autogenous DFGs by making incisions on the abdominal wall of volunteers and grafting DFGs attached with a suture to facilitate retrieval and histological study.

These showed that the circulation was re-established in the graft blood vessels at about four days by direct inosculation of capillaries, a process very similar to the 'take' of a full thickness skin graft.

After four days there was active circulation in the small vessels of the graft, degenerative changes of some fat cells and some disintegration of the cell membranes. There was also cell infiltration of the host tissues into the graft seen as clusters of polymorphonuclear lymphocytes and plasma cells. On the 10th day it was noted that the degenerating fat cells were being replaced by histiocytes and there was evidence of host capillaries penetrating into the graft. By 30 days it was obvious that there was some survival of fat cells from the graft but a certain percentage of degenerated fat cells were being replaced by histiocytes. The degeneration began with scattered fatty cysts and large masses of histiocytes that occupied the margins of the cysts and occasionally filled them. The graft contained numerous blood vessels and evidence of circulation. At three months larger cystic spaces were noted, there was less cellular infiltration and a greater number of normal looking fat cells.

At eight months there was a progressive diminution in the number of large histiocytes and round cells, a complete regeneration of the surviving fat cells in the graft and a disappearance of the cystic spaces. At 14 months the fat cells appeared like normal fatty tissue with a very thin connective capsule.

What percentage of DFGs for breast augmentation reabsorbs after one year? Verderame (13), in 1909, stated that the grafts reabsorb a "considerable amount" and advised the use of a larger transplant than necessary to fill the defect. Lexer (3) contended that only one-third of the fat grafts survived and that they did not grow in proportion to the individual. Gurney and Mann in 1938 (14) studied the behaviour of free fat grafts in rats and concluded that fat grafts should be transplanted in larger bulk than required since only a quarter to a half of the graft survived one year after transplantation. He also stated that the remaining part of the graft was the original and not a replacement or cell transformation from histiocyte into fat cell.

Rabson (15), in 1945, introduced the very important concept that the survival of DFGs depended on the vascularity of the recipient site. In other words, fat grafts placed on very vascular areas such as muscle or face or in younger individuals survived in a greater percentage than those placed in older people or in less vascular areas. He also stated that a single graft survives better than multiple small pieces of the same volume and concluded that autogenous fat grafts may actually increase in size if the patient increases in weight. 


\section{SELECTION OF PATIENTS}

Obese patients, smokers, the aged and unfit make poor candidates for DFGs. The ideal patient is the young, healthy mother who has undergone a post lactational breast involution and has flaccid wrinkled abdominal wall skin. An abdominal dermolipectomy coupled with an augmentation-mastopexy greatly enhances her looks and body image. I have not operated on patients with a history of breast cancer and I warn all my patients that there is a possibility of calcification appearing in the graft.

\section{SURGICAL TECHNIQUE}

In most cases I have taken the grafts from the skin that is usually discarded after doing an abdominal dermolipectomy. The technique differs in the atraumatic way tissues are handled and the timing of the different steps.

First, I prepare the recipient site by dissecting a pocket over the pectoralis major fascia of the same dimensions as the graft. The incision has to be long enough to permit an effortless entry of the graft (frequently periareolar). When removing implants from the submammary space one has to make sure that a total capsulectomy is also performed. Secondly, after having marked an ellipse in the infraumbilical area, the same as for a cosmetic dermolipectomy, I de-epithelialize the skin while still attached and then divide it at the Scarpa's fascia level. These grafts, usually less than $300 \mathrm{~mL}$ and not more than $3.5 \mathrm{~cm}$ in thickness, are treated very gently and immediately placed stretched out in the submammary pocket with the dermis side facing the pectoralis fascia, ensuring that there are no folds in the graft. I leave no drains and place no stitches to immobilize the grafts for I believe it is unnecessary and may traumatize the delicate DFGs. The breasts are immobilized with multilayered paper tapes and further supported with an elastic bra to be worn undisturbed for two to three weeks.

Attention is then turned back to the abdominal area which is treated like any cosmetic lipectomy. Adjuvant procedures such as undermining upwards, liposuction, tightening of the linea alba, umbilicoplasty and further defattening or skin trimming as one sees appropriate for the case are done (Figure 1).

\section{CASES AND COMPLICATIONS}

I have operated on a total of 36 patients with this technique: 31 bilateral augmentations and five unilateral. Figures 2,3,4 and 5 show the results in some of the patients. Only one had the grafts taken from the upper buttocks, with the rest taken from the lower abdomen.

Four patients, five grafts (three unilateral and one bilateral) did not take. Through a small wound dehiscence, yellow oily material oozed for three to six weeks. No attempt was made to remove the necrotic grafts. One of these developed an infection with definite pus coming from the wound and a whitish core of tissue came out after enlarging the wound. These patients were all middle aged.

There were no haematomas. Several fluid accumulations at the abdominal dermolipectomy site were the only complications in this area. 

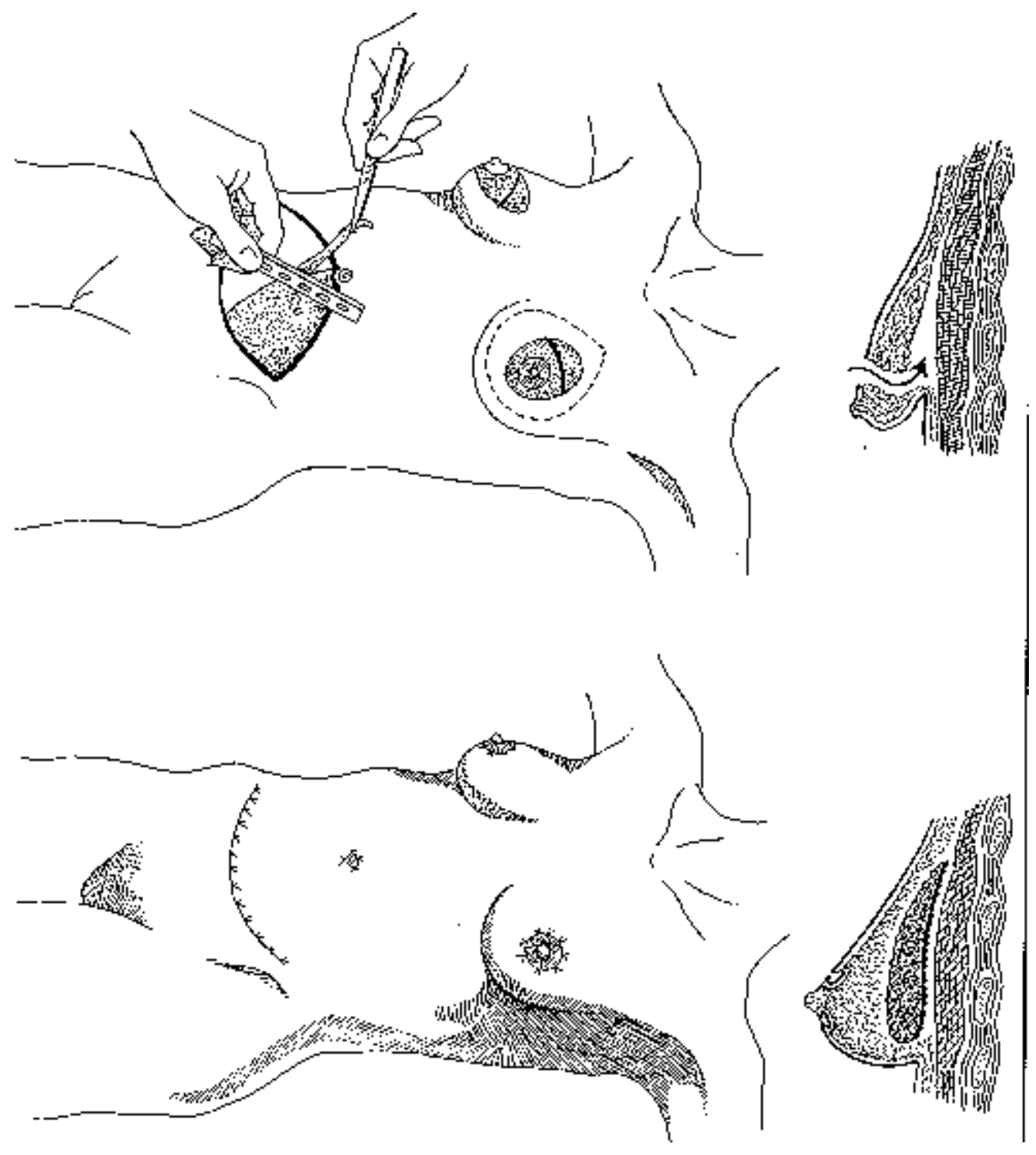

Figure 1) Procedure for breast augmentation using dermal fat grafts. (Upper left) Markings in the abdomen are done like any cosmetic dermolipectomy and in the breasts, usually, as a periareolar mastopexy. A dermatome blade is used to de-epithelialize all these areas. (Upper right) An incision on the de-epithelialized area above the areola is done to penetrate through the breast and dissect a pocket in the submammary space of the same dimensions as the graft. (Lower left) Closure of the abdomen by dragging the flaps, umbilicoplasty done with a small ' $V$ ' flap inset into the umbilicus. Pursestring periareolar closure. (Lower right) The stretched graft is lodged behind the breast with the dermis facing the muscle 

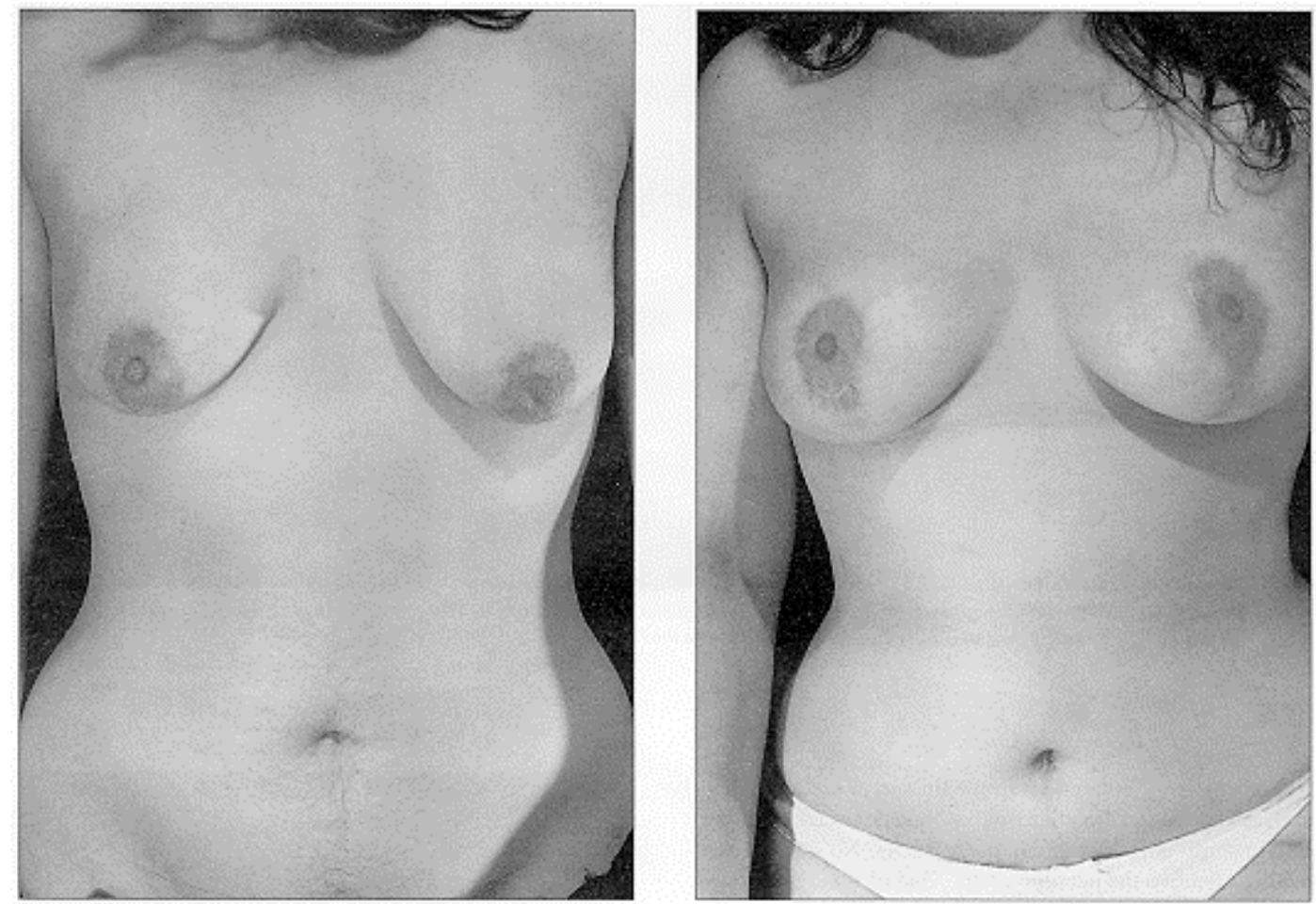

Figure 2) (Left) Thirty-two-year-old, G2 P2, ptotic and asymmetric breasts. (Right) Eight months after low abdominal lipectomy with umbilical stalk detachment, scar covered and periareolar mastopexy with dermis fat graft (DFG) augmentation
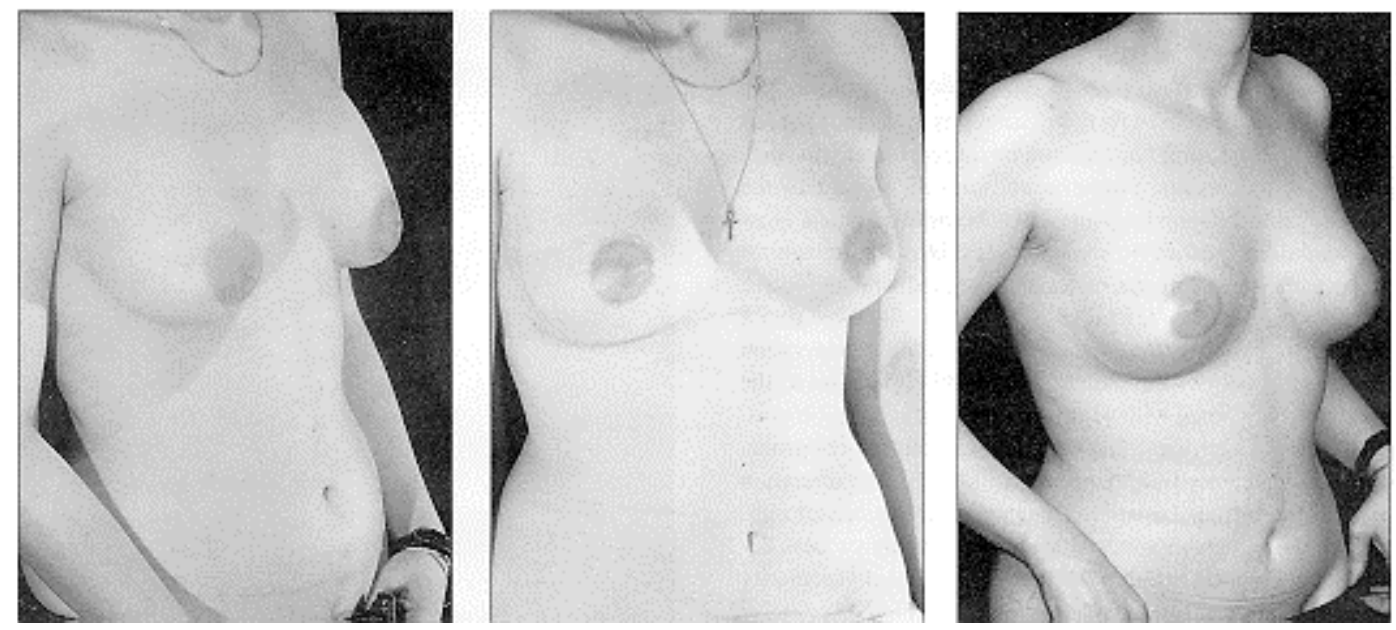

Figure 3) (Left) Twenty-nine-year-old with encapsulated subpectoral implants. (Middle) Implants removed, new submammary pocket through a periareolar mastopexy seen one year after DFGs. (Right) Two years latter, minimal resorption of DFG 

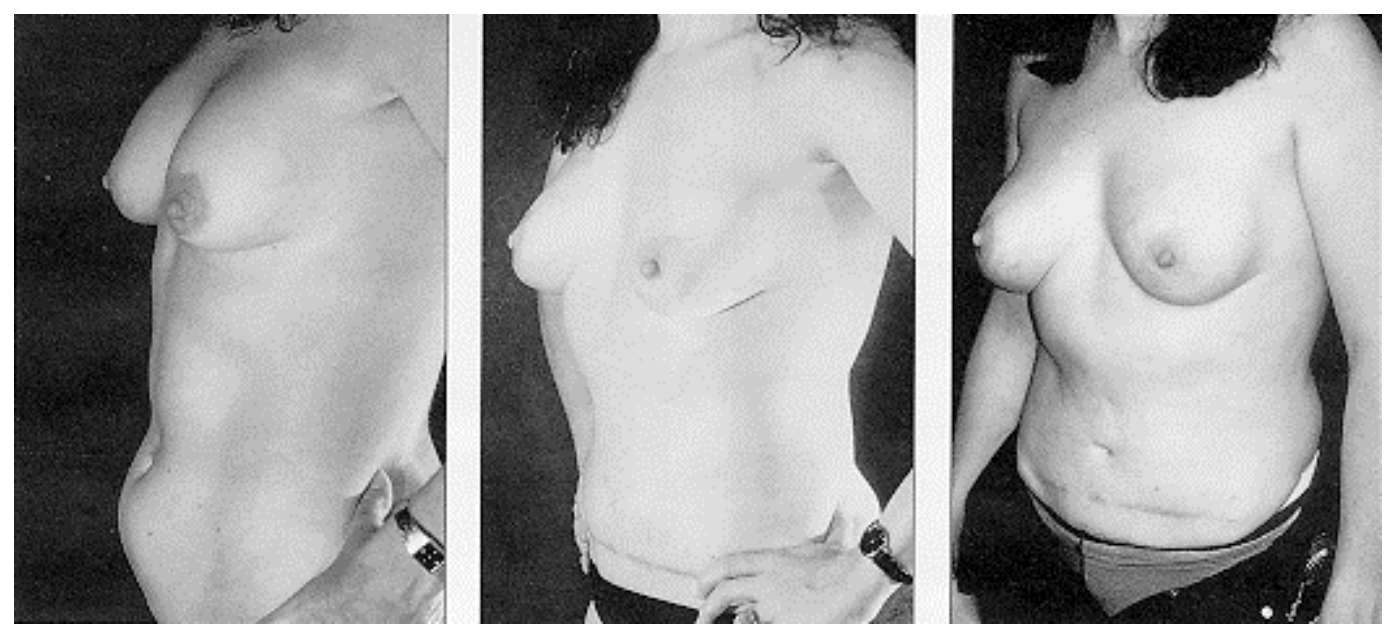

Figure 4) (Left) Thirty-five-year-old with multiple problems with her implants. (Middle) After one year of removal and replacement of the volume with DFGs. (Right) Two years later patient has increased weight and so have the breasts
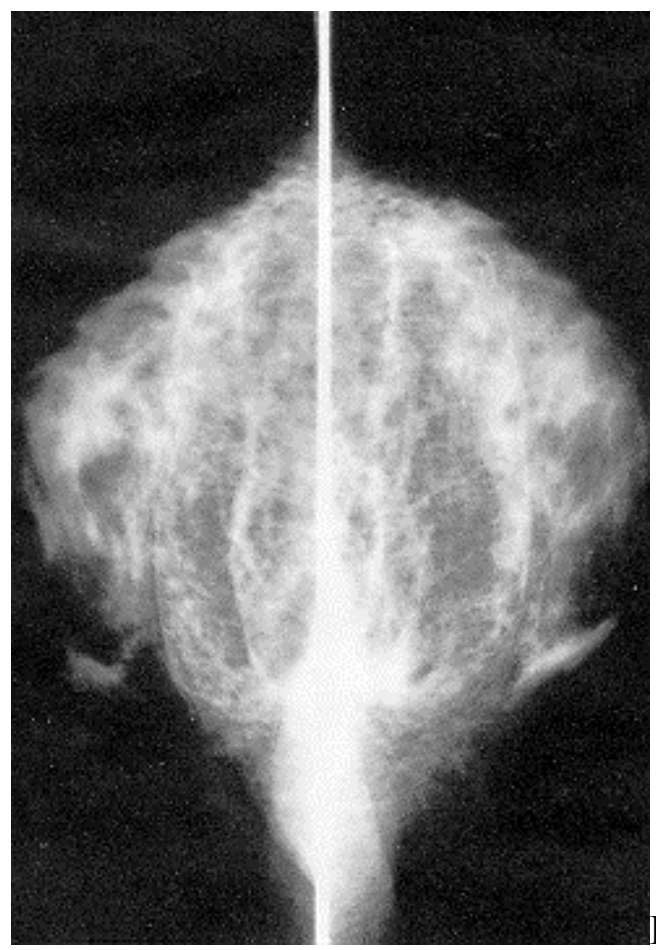

Figure 5) Mammogram done on breasts eight months after augmentation with DFGs, showing some cystic clear spaces indicative of future resorption

\section{DISCUSSION}

The idea of DFGs for breast augmentation is not new. The procedure has been used by many surgeons in the past but fell out of favour because patients and/or surgeons were discouraged with the results. Furthermore, with the advent of the more reliable silicone implants, DFGs became outdated. Now the pendulum (pushed by some lawyers) is swinging against the use of these foreign materials. A good and definitive operation is bilateral de-epithelialized TRAM flaps but donor site morbidity plus the expense and the 
long recuperation time greatly restrict the indications for this operation to the middle aged woman with a long history of implant problems. DFGs, on the other hand, can be done as an out-patient procedure and have very little donor morbidity and a recuperation period of two weeks usually. This operation has stricter indications than augmentation with implants for its success depends on the good health of the patient, the local vascularity and a delicate surgical technique.

Good 'takes' of these grafts can be expected in a woman with rich vascularity to her tissues; a young, healthy, nonsmoker who has suffered a post lactational breast involution makes the ideal candidate. Poor 'takes' can be expected in a patient who is middle aged, a smoker, overweight, who wants her implants removed and her protuberant abdomen reshaped at the same time.

The 'take' of the graft is also very dependent on technique. DFGs will not accept much manipulation, tugging or squeezing, and cauterizing may hinder the 'take'. The time the grafts are left exposed to the air will damage them; once they are deepithelialized on the patient they should be transferred immediately into the previously prepared submammary pocket. They should never be placed submuscularly. The grafts are usually $3.5 \mathrm{~cm}$ thick, approximately triangular and about $12 \mathrm{~cm}$ a side. Because the dermis is a densely vascular layer, when it is placed facing the pectoralis major fascia, also a very vascular layer, the possibility of the graft 'taking' will increase. This way of placing the graft differs from the approach used by Watson and others (11), who folded the graft in half or curled it like a snail with the fat towards the inside and placed the dermis side facing the less vascular mammary tissues. Many of these grafts were found to be extremely calcified years later (PE Wyshynski, personal communication).

In the series presented here, post traumatic calcifications are sometimes seen in mammagrams taken two years after the grafting. These are totally different from the pattern of microcalcification seen in cancer of the breast. Patients should be told that this may occur. It is advisable not to do DFGs in women with a family history of cancer of the breast.

\section{CONCLUSION}

A fresh look at DFGs for some breast augmentations is presented. Some women, influenced by the controversy surrounding silicone, refuse to have their breasts enhanced with implants. When they are young and healthy, especially after child birth and lactation, they are good candidates for abdominal dermolipectomy-mastopexyaugmentation with DFGs. These grafts are placed with their dermis side in contact with the pectoralis muscle fascia, they usually 'take' well and lose less than $50 \%$ of their initial volume.

\section{REFERENCES}

1. Neuber. Fetttransplantation. Chir Kong Verhandl 1893;1:66.

2. Czerny. Plastischer Ersatz der Brustdruse durch ein Lipom. Chir Kong Verhandl 1895;2:216.

3. Lexer E. Zwanzig Jahre Transplantations-forschung in der Chirurgie. Arch Klin Chir 1925;138:251-302.

4. Claux E, Evarant P, Piraux A, Darras T. Value and survival of free fat grafts in laminectomies. Acta Orthop Belg 1987;53:276-9. 
5. Saunders MC, Keller JT, Dunsker SB, Mayfield FH. Survival of autogenous fat grafts in humans and in mice. Connect Tissue Res 1981;8:389-94.

6. Langeskiold A, Osterman K, Valle M. Growth of fat grafts after operation for partial bone graft arrest: demonstration by computerized tomography scanning. J Pediatr Orthop 1987;7:389-94.

7. Smith BR, Beyer-Marcueli CK, Cheng HM, Pitts WC. Fate of primary orbital dermisfat grafts in guinea pigs. Ophthal Plast Reconstr Surg 1988;4(4):193-201.

8. Schorr N, Christenbury JD, Goldberg RA. Free autogenous pearl fat grafts to the eyelids. Ophthal Plast Reconstr Surg 1988;4:37-40.

9. Berson M.Dermal-fat transplants used in building up the breasts. Surgery 1945;15:451. 10. Bames HO. Augmentation mammoplasty by lipotransplants. Plast Reconstr Surg 1953;11:404.

11. Watson J. Some observations on free fat grafts: with reference to their use in mammoplasty. Br J Plast Surg 1959;12:263.

12. Peer LA, Walker JC. The behaviour of human tissue grafts. Plast Reconstr Surg 1951;7:6-23.

13. Verderame. Ueber Fetttransplantation de hadharenten Kochennarben am Orbitalrand. Klin Monatshefte Augenh 1909

14. Gurney CE, Mann FC. Experimental study of free fat transplantation. Surgery 1938;3:680.

15. Rabson SM. The fatty tissue: Normal anatomy and change in obesity. Am J Clin Path 1945;15:240-5. 